\title{
The IPCRG's teach the teacher programme: An educational initiative to promote improved management of difficult to manage asthma
}

Juliet McDonnell, Siân Williams, Jaime Correia de Sousa, Hilary Pinnock, Dermot Ryan

European Respiratory Journal 2016 48: PA2895; DOI: 10.1183/13993003.congress-2016.PA2895



Abstract

The IPCRG is a network of organisations committed to improving primary care assessment and treatment of chronic respiratory disease. We developed an evidencebased resource, SIMPLES (Ryan D, et al. Prim Care Respir J 2013;22:365-73) to aid structured asthma review for difficult to manage asthma. An educational initiative was introduced to disseminate research findings from U-BIOPRED and promote improved primary care management. We aimed to support participants from seven European countries to design and plan local programmes of education:teaching clinical colleagues key messages about difficult to manage asthma, encouraging local adaptation of existing IPCRG resources. These took place in autumn 2015 involving over 230 health professionals - including early career and GPs with a special interest in asthma/COPD, specialist nurses and others. We proposed an evaluation framework(Guskey,T.Teachers\&Teaching 2002;8:3, 381-391) which includes - i) participant reaction, ii) learning, iii) organisational changes, iv) use of new knowledge and v) impact on practice and service users. Programmes were well received by participants. There were many challenges encountered: in assessing local learning needs, setting up education programmes and supporting clinical practice change. The impact on participants' clinical practice and service users is more challenging to demonstrate and will require more time to evaluate. We reflect on the challenge of meaningful evaluation of practice change. These insights are important in thinking about the design, implementation and evaluation of clinical educational programmes globally.

Funding: IPCRG/U-BIOPRED(IMI JU project no.115010).

Asthma - management Education Primary care

\section{We recommend}

The IPCRG's teach the teacher programme: An educational initiative to promote improved management of difficult to manage asthma

Juliet McDonnell et al., European Respiratory Journal

The quest for the grail: multidimensional efforts for understanding and targeting severe asthma.

Mina Gaga et al., European Respiratory Journal

A guide to the translation of the Global Initiative for Asthma (GINA) strategy into improved care.

Louis-Philippe Boulet et al., European Respiratory Journal

The era of research collaborations: new models for working together

Ratko Djukanović et al., European Respiratory Journal

Supported self-management for asthma

Hilary Pinnock, Breathe
Resource-stratified implementation of a community-based breast cancer management programme in Peru

Catherine Duggan et al., The Lancet Oncology

The implementation of the Plan Esperanza and response to the imPACT Review

Tatiana Vidaurre et al., The Lancet Oncology

Standards for Reporting Implementation Studies (StaRI) Statement Hilary Pinnock, The BMJ

Establishment of ethical oversight of human research in El Salvador: lessons learned

Miguela A Caniza et al., The Lancet Oncology

The windtunnel test

Mr John Ratcliffe, Structural Survey 
29/12/2017 The IPCRG's teach the teacher programme: An educational initiative to promote improved management of difficult to manage asthma | Eu...
$\nabla$ Emai
(C) Request Permissions
Alerts
$\rightarrow$ Share
C Citation Tools

Jump To

Article

Info \& Metrics

Tweet Gosto 0 G+

More in this TOC Section

Related Articles

No related articles found.

Google Scholar

Navigate

Home

Current issue

Archive

About the ERJ

Journal information

Editorial board

Reviewers

CME

Press

Permissions and reprints

Advertising

The European Respiratory Society

Society home

myERS

ERS publications

European Respiratory Journal

ERJ Open Research

European Respiratory Review

Breathe

ERS books online

ERS Bookshop

Help

Feedback

For authors

Instructions for authors

Submit a manuscript

Author services and promoting your work

For readers

Alerts

Subjects

Collections

Dndracte

THANK YOU FOR ACCEPTING COOKIES

You can now hide this message or find out more about cookies. 